\title{
ANATOMICAL VENTRICULAR HYPERTROPHY PATTERNS IN COMPLETE TRANSPOSITION OF THE GREAT VESSELS*
}

\author{
BY \\ HOMOBONO B. CALLEJA $\dagger$, DON M. HOSIER $\ddagger$, AND MARIA Z. GRAJO§ \\ From the Kinder Key Heart Laboratory, Children's Hospital, Columbus, Ohio, U.S.A.
}

Received October 11, 1963

Ventricular hypertrophy in congenital heart disease is related in general to two hæmodynamic changes, systolic overloading and diastolic overloading. A combination of systolic and diastolic overloading is not uncommon. Shunts like those with ventricular septal defect, atrial septal defect, and patent ductus arteriosus give rise to a diastolic overload. Obstruction to outflow in either ventricle produces a systolic type of overloading.

In complete transposition of the great vessels, the right ventricle bears the higher systemic pressure while the left ventricle has the normally lower pulmonary pressure. With this arrangement hypertrophy of the right ventricle is expected to develop. However, the presence of shunts and other defects may bring important hæmodynamic pressure changes in the two ventricles in a way that hypertrophy of one or both ventricles will be less predictable. This report shows the relation of these factors in the production of anatomical ventricular hypertrophy patterns.

\section{MATERIAL AND Method}

The cases of complete transposition of the great vessels in this study are limited to those in which the aorta and the pulmonary trunk take off exclusively from the ventricle opposite to where they normally arise. Other anomalies in the origin of the aorta and the pulmonary trunk from the right ventricle, TaussigBing complex, the so-called "corrected transposition," and overriding of the aorta or the pulmonary trunk, are excluded. Cases of transposition of the great vessels with single ventricle are included because the situation is analogous to a big ventricular septal defect in which the pressures in the right and left ventricles are the same; and hence, clinically difficult to separate. That complete transposition of the great vessels can be diagnosed with confidence at necropsy in spite of a single ventricle doubly underlines the importance of the anatomical relation of the two great vessels to each other. The presence of a single ventricle provides the much needed shunt for survival of the newborn. To exclude these cases would be to commit a grave error of placing an associated defect over and above the more basic anomaly. Of cases of single ventricle 80 per cent have complete transposition of the great vessels (Keith, Rowe, and Vlad, 1958), while only 6 per cent of cases of complete transposition of the great vessels have single ventricle (Miller, Baffes, and Wilkinson, 1958).

In the Children's Hospital, Columbus, Ohio, 67 patients diagnosed as having complete transposition of the great vessels were seen from January 1953 to March 1960 inclusive (Table I). The diagnosis was confirmed by angiocardiography or cine-angiocardiography with or without surgery in 17 and verified at necropsy in 42 patients. In the angiocardiogram or cine-angiocardiogram, the aorta is seen to arise anteriorly from the right ventricle. The pulmonary trunk may be visualized faintly, appearing later than the aorta and located posteriorly to it. At necropsy, ventricular hypertrophy is presumed to be present if

\footnotetext{
* This study was supported in part by Mrs. Bertha Amerman, Ingleswood, California, U.S.A.

$\uparrow$ Present address: Amerman Heart Clinic, 316 Oregon Boulevard, Philadelphia, Pa., U.S.A.

$\ddagger$ Present address: Ohio State University Health Centre, Ohio, U.S.A.

$\S$ Present address: Faculty of Medicine University of Santo Tomas, Manila, Philippines.
} 
TABLE I

\begin{tabular}{|c|c|c|c|}
\hline \multicolumn{3}{|c|}{ Diagnosis } & No. \\
\hline $\begin{array}{l}\text { At necropsy } \\
\text { Angiocardiograph } \\
\text { Clinical alone }\end{array}$ & $\begin{array}{cccc} & . . & . . & \ldots \\
\text { ine-angiocardiograph } & \ldots \\
. & \ldots & . & \ldots\end{array}$ & $\begin{array}{l}\ldots \\
\ldots \\
\ldots\end{array}$ & $\begin{array}{r}42 \\
17 \\
8\end{array}$ \\
\hline Total & $\ldots$ & .. & 67 \\
\hline
\end{tabular}

the normal value for ventricular thickness according to age (Sodi-Pallares et al., 1958) is exceeded. In 28 cases complete measurements of the thickness of the free walls of the ventricles were recorded. Associated anomalies, particularly the type and number of shunts, were noted.

\section{RESULTS}

Table II shows the type and number of communications between the pulmonary and the systemic circulations in 40 patients proved by necropsy and/or angiocardiogram. Ventricular septal defect was the only shunt present in 9 patients $(22.5 \%)$. In $4(10 \%)$, a patent ductus arteriosus was the only associated shunt, and in $2(5 \%)$ an atrial septal defect provided the only communication. One patient (Case 40) had no apparent shunt at necropsy. A combination of 2 or 3 shunts was encountered in 6 patients $(15 \%)$. A single ventricle was found in $6(15 \%)$, and anomalous pulmonary veins were associated with a single ventricle in 1 (Case 34).

Ventricular hypertrophy was assessed at necropsy by measuring the free walls of the right and left ventricles. Excluding those with a single ventricle (Cases 34, 35, 36), the thickness of the wall of the right ventricle was recorded in 27, and that of the left ventricle in 25 patients. The thickest right ventricular wall measured $10 \mathrm{~mm}$. This occurred in Case 7 with a ventricular septal defect. A 7-day-old patient with a single ventricle (Case 35) had a ventricular wall varying from 10 to $15 \mathrm{~mm}$. in thickness. The left ventricle was thicker than normal in 15 patients $(60 \%)$, but only 2 had isolated left ventricular hypertrophy (Cases 10,11). Of the 25 patients with right and left ventricular measurements, $9(36 \%)$ had isolated right ventricular hypertrophy and $13(32 \%)$ had combined ventricular hypertrophy. Altogether, increased thickness of the right ventricle was found in 24 of

TABLE II

Shunts Associated with Transposition*

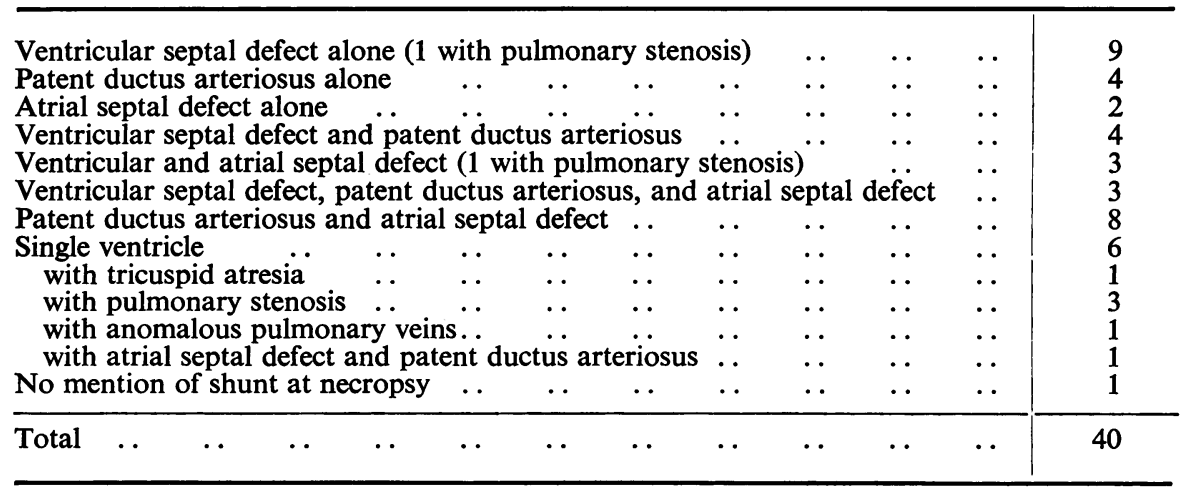

* Proved by necropsy, angiocardiogram, and/or surgery. 
TABLE III

Transposition with Single Shunts

\begin{tabular}{|c|c|c|c|}
\hline Case No. & Age (mth.) & R.V. (mm.) & L.V. (mm.) \\
\hline $\begin{array}{l}\text { With ventricular } \\
1 \\
2 \\
3 \\
4 \\
5 \\
6 \\
7 \\
8 \\
9\end{array}$ & $\begin{array}{l}4 \mathrm{dy} . \\
1 \frac{1}{2} \\
3 \\
3 \\
3 \\
4 \\
5 \\
7 \\
11\end{array}$ & \multicolumn{2}{|c|}{\begin{tabular}{c|l} 
Cine-angiocardiogram \\
Angiocardiogram, operation \\
5 \\
4 & 5 \\
8 & 6 \\
$?$ & 7 \\
10 & $?$ \\
6 & 5 \\
7 & $6-8$
\end{tabular}} \\
\hline $\begin{array}{c}\text { With patent duct } \\
10 \\
11 \\
12 \\
13\end{array}$ & $\begin{array}{l}\text { sus } \\
2 \\
2 \\
1^{\frac{1}{2}}\end{array}$ & $\begin{array}{l}3 \\
3 \\
5 \\
4\end{array}$ & $\begin{array}{l}6 \\
6 \\
8 \\
6\end{array}$ \\
\hline $\begin{array}{c}\text { With atrial septal } \\
14 \\
15\end{array}$ & $\begin{array}{l}2 \\
4\end{array}$ & $\begin{array}{l}8 \\
4 \cdot 5\end{array}$ & $\begin{array}{l}4 \\
3-4\end{array}$ \\
\hline
\end{tabular}

27 patients $(89 \%)$. Two patients (Cases 10,11) had normal thickness of the right ventricle at the age of 2 days, and 1 patient (Case 30) at the age of 2 weeks showed neither right nor left ventricular hypertrophy.

Shunts were divided into single or multiple. Patients with single ventricle formed a third group. A single shunt (Table III) was provided by (1) ventricular septal defect, (2) patent ductus arteriosus,

TABLE IV

Transposition With MUltiple ShUNTS

\begin{tabular}{|c|c|c|c|}
\hline Case No. & Age (mth.) & R.V. (mm.) & L.V. (mm.) \\
\hline $\begin{array}{c}\text { With ventricular } \\
16 \\
17 \\
18 \\
19\end{array}$ & $\begin{array}{c}\text { defect and paten } \\
4 \mathrm{dy} . \\
1 \frac{3}{4} \\
2 \\
2 \frac{1}{2} \mathrm{wk} .\end{array}$ & $\begin{array}{c}s \text { arteriosus } \\
4 \\
7 \\
7 \\
8\end{array}$ & $\begin{array}{l}2 \\
4 \\
5\end{array}$ \\
\hline $\begin{array}{l}\text { With ventricular } \\
\qquad \begin{array}{c}20 \\
21 \\
22\end{array}\end{array}$ & $\begin{array}{c}\text { rial septal defect } \\
1 \\
2 \frac{1}{2} \\
11\end{array}$ & $\begin{array}{l}6 \\
5 \\
6\end{array}$ & $\begin{array}{l}7 \\
5 \\
?\end{array}$ \\
\hline
\end{tabular}

With ventricular and atrial septal defect and patent ductus arteriosus

\begin{tabular}{l|c|cc}
23 & 7 dy. & 5 & $\mid$ \\
24 & 1 & Cine-angiocardiogram & 5 \\
25 & $1 \frac{1}{4}$ & 5 & 6
\end{tabular}

With patent ductus arteriosus and atrial septal defect

\begin{tabular}{l|l|l|l}
26 & 2 dy. & 5 & 8 \\
27 & 2 dy. & $?$ & $?$ \\
28 & 3 dy. & 4 & 5 \\
29 & 5 dy. & Cine-angiocardiogram & 2 \\
30 & $\frac{1}{2}$ & 3 & 6 \\
31 & 19 dy. & 4 & 6 \\
33 & 21 dy. & 5 & $6-7$ \\
33 & $2 \frac{1}{2}$ & 9 & 5
\end{tabular}


TABLE V

Transposition With Single Ventricle

\begin{tabular}{c|c|c|l}
\hline Case No. & Age & Ventricle (mm.) & \multicolumn{1}{|c}{ Anomalies } \\
\hline 34 & $2 \mathrm{dy}$. & 3 & Anomalous pulmonary veins \\
35 & $7 \mathrm{dy}$. & $10-15$ & Atrial septal defect; patent ductus arteriosus \\
36 & $10 \mathrm{wk}$. & $5 \mathrm{k}$. & Pulmonary stenosis \\
37 & $2 \mathrm{yr}$. & Angiocardiogram; operation & Tricuspid atresia; patent foramen ovale \\
38 & $6 \mathrm{yr}$. & Angiocardiogram; operation & Pulmonary stenosis \\
39 & Pulmonary stenosis \\
\hline
\end{tabular}

and (3) atrial septal defect. There were 9 patients $(22.5 \%)$ with ventricular septal defect, and 6 had measurement of both ventricles at necropsy. Combined ventricular hypertrophy was found in 4; the left ventricular wall was thicker than the right in 3; and the right ventricular wall twice as thick as the left in Case 7. Four patients $(10 \%)$, who came to necropsy, all had patent ductus arteriosus as the only shunt. All showed thicker left ventricular wall compared with the right. The right ventricle was normal in 2, both only 2 days old. Another 2 had combined ventricular hypertrophy with the left being thicker than the right. Atrial septal defect was the only communication in 2 patients $(5 \%)$ : both showed isolated right ventricular hypertrophy at necropsy; the left ventricle was thinner than normal.

Patients with multiple shunts are shown in Table IV. Four patients $(10 \%)$ had a ventricular septal defect and a patent ductus arteriosus. Necropsy on 3 showed isolated right ventricular hypertrophy. Ventricular septal defect combined with atrial septal defect was found in 3 patients $(7.5 \%)$ at necropsy. Both ventricles were found to have thicker than normal value, but they maintained about the same ratio as at birth. Ventricular septal defect was also associated with patent ductus arteriosus and atrial septal defect in 3 other patients $(7.5 \%)$. The two cases at necropsy showed biventricular hypertrophy. Eight patients $(20 \%)$ had patent ductus arteriosus combined with atrial septal defect. Biventricular hypertrophy was present in 3 and isolated right ventricular hypertrophy in 1 . Case 30 had a normal right ventricle but the left was hypoplastic.

Three patients with single ventricle (Cases $34,35,37$ ) had additional shunt or shunts. In all, 21 patients $(52.5 \%)$ had multiple shunts. Table V shows 6 patients with single ventricle $(15 \%)$. Three of them had pulmonary stenosis; another 3 had additional shunts in the form of total anomalous pulmonary venous drainage, atrial septal defect, patent ductus arteriosus, and patent foramen ovale. In one child who died at 4 months right ventricular hypertrophy was found at necropsy but no apparent shunts: bronchopulmonary anastomosis must have been present to sustain life after birth.

\section{Discussion}

Complete transposition of the great vessels associated with ventricular septal defect, patent ductus arteriosus, and atrial septal defect as single shunt constituted 37.5 per cent of our cases; whereas more than 50 per cent had multiple shunts. The relation between the type and number of shunts and the anatomical ventricular hypertrophy patterns is shown in Table VI.

The physiological data derived by catheterization studies in patients with complete transposition of the great vessels have been reported by Noonan et al. (1960). Patients with intact ventricular septum had a left-to-right shunt through the atrial septal defect and a right-to-left shunt may occur at the same level or through a patent ductus arteriosus. Those with ventricular septal defect had bidirectional shunt at the ventricular level and either a left-to-right or right-to-left shunt through the atrial defect. In general, these physiological data agree with the anatomical ventricular hypertrophy patterns found in this study. 
TABLE VI

Relation of Shunt to Ventricular Hypertrophy Pattern

\begin{tabular}{|c|c|c|}
\hline \multicolumn{2}{|r|}{ Shunt } & \multirow{2}{*}{$\begin{array}{l}\text { Ventricular hypertrophy pattern } \\
\text { (anatomical) }\end{array}$} \\
\hline No. & Type & \\
\hline I. Single & $\begin{array}{l}\text { Ventricular septal defect } \\
\text { Patent ductus arteriosus } \\
\text { Atrial septal defect }\end{array}$ & $\begin{array}{l}\text { Combined ventricular hypertrophy-left ventricle } \\
>/<\text { right ventricle } \\
\text { Left ventricular hypertrophy-left ventricle }> \\
\text { right ventricle (even if right ventricular hyper- } \\
\text { trophy is present) } \\
\text { Right ventricular hypertrophy }\end{array}$ \\
\hline II Double & $\begin{array}{l}\text { Ventricular septal defect plus patent ductus } \\
\text { arteriosus } \\
\text { Ventricular septal defect plus atrial septal defect } \\
\text { Patent ductus arteriosus plus atrial septal defect }\end{array}$ & $\begin{array}{l}\text { Right ventricular hypertrophy } \\
\text { Combined ventricular hypertrophy (ventricular } \\
\text { ratio similar to that at birth) } \\
\text { Combined ventricular hypertrophy/right ventri- } \\
\text { cular hypertrophy }\end{array}$ \\
\hline III. Triple & $\begin{array}{l}\text { Ventricular septal defect plus patent ductus } \\
\text { arteriosus plus atrial septal defect }\end{array}$ & Combined ventricular hypertrophy \\
\hline
\end{tabular}

Isolated right ventricular hypertrophy is produced either by a single shunt due to an atrial septal defect or by a shunt combination of a patent ductus arteriosus and a ventricular septal defect. Left ventricular hypertrophy, isolated or combined with mild right ventricular hypertrophy, is produced exclusively by a patent ductus arteriosus. Biventricular hypertrophy results from ventricular septal defect as a single shunt or from multiple shunts.

If the shunt is due solely to a patent ductus arteriosus, left ventricular hypertrophy invariably results (Fig. 1). The thickness of the free wall of the left ventricle exceeds that of the right, even if the latter is also hypertrophied. It appears that the ductus arteriosus carries a shunt flow from the aorta in the right to pulmonary artery in the left. A small shunt from the pulmonary artery to the aorta has to occur for oxygenation of vital centres, but is not adequate to sustain postnatal life. From clinical experience survival is limited to a few days or weeks after birth. However, when patent ductus arteriosus is combined with ventricular septal defect, isolated right ventricular hypertrophy uniformly occurs (Fig. 2). The presence of a ventricular septal defect provides a shunt from left to right further overloading the right ventricle which is already under systemic pressure. The shunt at the ventricular level produces in effect a decompression of the left ventricle at the expense of right ventricle. The result is right ventricular hypertrophy rather than left.

The combination of a patent ductus arteriosus and an atrial septal defect tends to produce hypertrophy of both ventricles (Fig. 3). Diastolic overloading of the right ventricle is produced by a left-to-right shunt at the atrial defect. This shunt has no decompressing effect upon the left ventricle; hence, left ventricular hypertrophy remains.

When ventricular septal defect is the only shunt present combined ventricular hypertrophy develops (Fig. 4), and the right ventricle may be thicker or thinner than the left. Such factors as pulmonary vascular resistance, systemic pressure, size of ventricular septal defect, and the amount of shunt flow are probably important determinants of the final ratio between the two hypertrophied ventricles. Therefore, although combined hypertrophy may be predictable, the ratio between the two ventricles is not.

Both patients with atrial septal defect had isolated right ventricular hypertrophy. Diastolic overloading of the right ventricle occurs due to a left-to-right shunt at the atrial level. For survival a right-to-left shunt must also operate (Fig. 5). Three patients who had both atrial septal defect and ventricular septal defect showed combined ventricular hypertrophy. A bidirectional shunt probably operates at the atrial and ventricular levels (Fig. 6). A third additional shunt in the form of a patent 


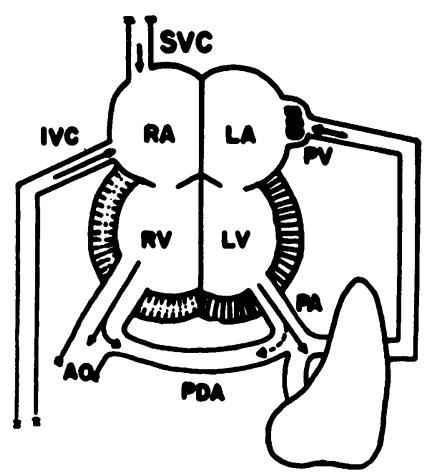

Fig. 1.

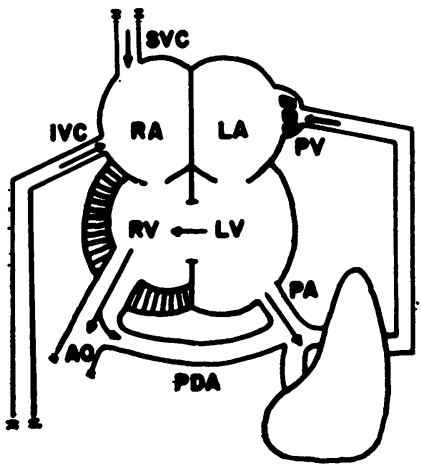

Fig. 2.

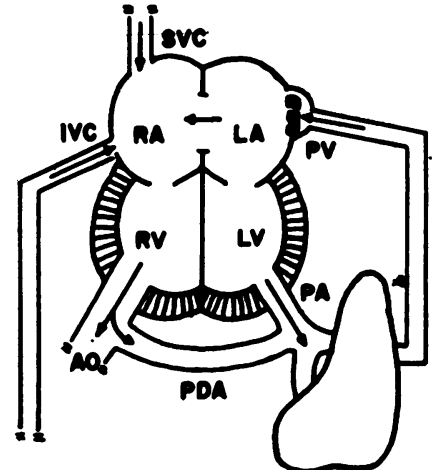

Fig. 3.

FIG. 1, 2, and 3.-Transposition of the great vessels, with patent ductus arteriosus (4 patients) in Fig. 1; with patent ductus arteriosus and ventricular septal defect (4 patients) in Fig. 2 ; and patent ductus arteriosus and atrial septal defect (8 patients) in Fig. 3.

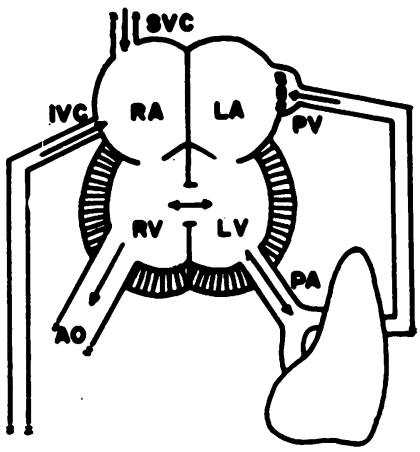

Fig. 4.

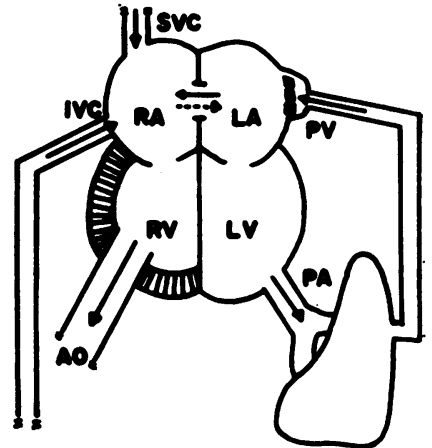

Fig. 5.

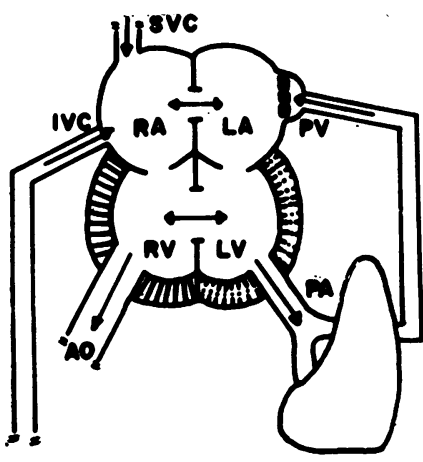

Fig. 6.

FIG. 4, 5, and 6.-Transposition of the great vessels with ventricular septal defect (9 patients) in Fig. 4; with atrial septal defect (2 patients) in Fig. 5; and with ventricular septal defect and atrial septal defect (3 patients) in Fig. 6.

ductus arteriosus produces also a biventricular hypertrophy pattern. Two such patients were studied at necropsy: both showed combined ventricular hypertrophy.

The presence of a normal right ventricle in 3 patients (Cases 10,11,30) is of interest in that all had patent ductus arteriosus. Cases 10 and 11 had a patent ductus arteriosus as the only shunt, and both died at the age of 2 days with left ventricular hypertrophy. The third patient (Case 30) had an atrial septal defect as an additional shunt, and he died at 2 weeks: the left ventricle was hypoplastic.

Pulmonary stenosis was present in one patient with ventricular septal defect and in another with combined ventricular and atrial septal defects. Three other patients had a single ventricle. The common denominator for the occurrence of pulmonary stenosis appears to be a shunt at the ventricular level. Both patients with ventricular septal defect had biventricular hypertrophy. Pulmonary stenosis provides a regulatory mechanism preventing flooding of the lungs and at the same time keeping the delicate balance between the pulmonary and systemic circulations.

One patient (Case 40) who had no apparent shunt at necropsy lived up to 4 months: the foramen ovale was completely closed and there was no evidence of any ventricular septal defect; the pulmonary veins were normal and the ductus arteriosus was fibrous with no patency. It is probable that large bronchial arteries shunted blood from the aorta to the pulmonary circulation. The role of these bronchial communications has been pointed out by Lev and Saphir (1937) and later demonstrated by Cudkowicz and Armstrong (1952) using injection techniques. 


\section{SUMMARY}

In all, 67 patients with complete transposition of the great vessels were seen at the Children's Hospital, Columbus, Ohio during seven years. The type and number of communications were confirmed by necropsy and/or angiocardiogram in 40 patients. A single shunt was found in 37.5 per cent and was due to a ventricular septal defect in 22.5 per cent, a patent ductus arteriosus n 10 per cent, and an atrial septal defect in 5 per cent. A combination of two or three shunts was encountered in 21 patients $(52 \cdot 5 \%)$. Six patients $(15 \%)$ had a single ventricle, and there was one with no apparent shunt at necropsy.

Complete measurements of the free walls of the ventricles were recorded in 28 cases. Anatomical ventricular hypertrophy patterns were analysed in relation to the type and number of shunts. The hypertrophy patterns that were evolved from this study have been set out in Table VII.

\section{REFERENCES}

Cudkowicz, L., and Armstrong, J. B. (1952). Injection of the bronchial circulation in a case of transposition. Brit. Heart J., 14, 374.

Keith, J. D., Rowe, R. D., and Vlad, P. (1958). Heart Disease in Infancy and Childhood. Macmillan, New York.

Lev, M., and Saphir, O. (1937). Transposition of the large vessels. J. techn. Meth., 17, 126.

Miller, R. A., Baffes, T. G., and Wilkinson, A. A. (1958). Transposition of the great vessels: diagnostic considerations and surgical therapy. Pediat. Clin. N. Amer., 5, 1109.

Noonan, J. A., Nadas, A. S., Rudolph, A. M., and Harris, G. B. C. (1960). Transposition of the great arteries. A correlation of clinical, physiologic and autopsy data. New Engl. J. Med., 263, 592, 637, 684, and 739.

Sodi-Pallares, D., Portillo, B., Cisneros, F., de la Cruz, M. V., and Acosta, A. R. (1958). Electrocardiography in infants and children. Pediat. Clin. N. Amer., 5, 871. 